with his left hand most other sinistral accomplishments will be added unto him. In our own manifold profession ambidexterity is a great equipment. In laryngoscopy, in ophthalmoscopy, in palpation, in percussion, and in examinations per vias naturales it is useful. Ambidexterity would prevent many occupation pareses. It would tend to a more equal use, and to an alternative and reciprocally resting use, of the two sides of the brain. It might prevent, or help in the cure of, some cases of hemicrania. Perhaps it might prevent some cases of hemiplegia.

\section{THE DIAGNOSIS OF DIPHTHERIA.}

By H. B. DONKIN, M.D., F.R.C.P.,

One of the Commissioners of Prisons ; Consulting Physician to the Westminster Hospital and to the East London Hospital for
Children, Shadwell.

Tre question of the respective rôles of the physician and pathologist in the diagnosis of diphtheria, which is so ably discussed in Dr. Andrewes's paper reported in the BRITISH Medical Jodrnal of September 29 th, is one of the highest practical importance, as well as of great scientific interest. In these days many educated and thoughtful laymen, whether privately interested in this and kindred matters, or, as public men, charged with the ordering of schools and other institutions, are quite as well acquainted as the average medical man with the discoveries of modern bacteriology. It is imperatively necessary, then, in the cause of rightiul practice, that the real bearings of the bacteriological factor on dia. gnosis be clearly understood by the medical profession at large, and plainly and frankly stated, when stated at all, to the intelligent public.

To this end, as regards diphtheria at least, the well-argued paper by Dr. Andrewes above referred to appears to be of a value which cannot be overrated, and is woithy of widespread and serious notice. After giving in detail and step by step the clearest reasons for not placing absolute reliance on any of the bacteriological tests in the diagnosis of diphtheria, including even those of inoculation and control experiments with antitoxin upon animals, Dr. Andrewes practically sums up with the following dictum which was endorsed by subsequent expert speakers at the discussion: "In every case the ultimate responsibility of diagnosis must rest with the physician and not with the bacteriologist."

Now it is not to be denied that ever since the time when, partly as the result of the theories of the identity of "croup" and "diphtheria," and of the nniversally "diphtherial" nature of "membranous deposits," which increasingly pervaded the schools, men were led to seek more diligently, and at last to find what is believed to be the specific and causa bacillus of diphtheria, the growing and almost unopposed tendency has been for the physician to throw the ultimate responsibility of diagnosis in this disease upon the bacteriologist. This practice has now, indeed, spread so widely that it is not too much to say that the average doctor regards the exclusively bacteriological diagnosis of diphtheria as part of his scientific creed, abolishing the multiform and confessed difficulties met with along the thorny path of clinical observation, and substituting therefor a royal and simple road to a definite result. Nor is it perhaps only to a laudable desire of welcoming the new fruits of scientific research that this recent belief and practice are attributable, but also, it would seem, to that love of finality in inquiry, and that tendency to avoid difficulties and responsibility which mark the minds of many, if not most, men of all sorts.

In my experience I have come across several instances, similar to that striking one adduced by Dr. Andrewes, of more or less disastrous results arising from the custom of doctors to cast all their cares on the bacteriologists and to place implicit trust in their pronouncements. It is doubtless true, as Dr. Andrewes says, that the physician may often supply imperfect information to the bacteriologist, and misinterpret and misapply the report he receives; and, on the other hand, it is to be remembered that not every bacteriologist is 80 philosophic and explicit as Dr. Andrewes. Wherever the fault mainly lies, the errors arising from this misplaced faith are not to be ignored; and the conclusion that a case is not diphtheria which afterwards is proved to be 80 , with all its disastrous consequences, is only more deplorable than the opposite mistake of causing vain panic and sometimes money losses of the gravest kind by giving a false alarm of diphtheria. It would be of great interest to know, for example, the extent of the injury done to the proprietor of that school, where, as Dr. Andrewes tells us, several healthy boys with healthy throats and noses were stated by several bacteriologists to be the hosts of diphtheria bacilli, or of bacilli "morphologically indistinguishable" therefrom. A school might well be ruined by such a mishap as this, which is plainly and only attributable to an ill-informed and overweening faith on the part of either schoolmaster or doctor, or both, in what to them is one of the new things in science.

Every word of Dr. Andrewes's invaluable paper might be usefully studied and weighed, not only by doctors but also by all intelligent people, especially those connected with public institutions of all kinds where human beings congregate. The remarks, also, of Dr. Klein and of Dr. T. D. Lister are worthy of close attention. I well remember the series of careful observations made by Dr. Iister not many years ago, in the wards and laboratory of the East London Hospital for Children - some of the latter ones at my request-and I can add to his remarks that he found what both he and other skilled observers pronounced to be the Klebs-Loeffler organism, and not another, in the voses of several children neither suspected of diphtheria nor subsequently its victimsnoses, moreover, of which some "ran" or " snuffled" more or less, some not at all.

It is not, of course, to be doubted that from time to time and in certain cases the bacteriological factor is important in the diagnosis of diphtheria, and, among other lessons, this method of research has taught us that we have very good cause to adhere, as some of us have always adhered, to the belief that not all membranous cases of laryngitis or sore throat are diphtherial. But on carefully studying all Dr. Andrewes's remarks, and bearing in mind all the pitfalls which beset the bacteriologist in this matter, and the safeguards which are essential to his procedure, one may dcubt a little whether a strictly logical criticism altogether justifies. even that amount of actually practical weight which the writer of the paper seems inclined to attribute to the bacteriological factor in the diagnosis of diphtheria.

The practical teaching which the present state of knowledge on this difficult question seems to admit is apparently somewhat as follows :

I. Diagnosticians should at once regard and treat, without waiting for a bacteriological report, all cases as diphtheria, in which the clinical signs and symptoms are such as would have raised but little or no doubt in their minds as to their nature in the days before the coming of the bacillus.

2. They should also regard and treat as diphtheria all cases which, although lacking the usual clinical "stigmata," are shown by bacteriological examination to be associated with bacilli whose products kill animals and cause the characteristic lesions ; albeit even here they may be in error, though on the better side.

3. The mere presence of bacilli (in the nose or elsewhere) "morphologically indistinguishable" from the pure "diphtheria bacillus," the host being healthy and inoculation results negative, may probably be ignored in practice, and so also. may all negative bacteriological reports in cases where there are any clinically recognised symptoms or signs of the concrete disease. In fine, does not the diagnosis of diphtheria still rest mainly for its surest foundation on the old ground of careful clinical observation, tempered and aided in some cases it may be, by a judicial study of the report of the bacteriologist?

The San Remo Home for Ladies has received ten invalid ladies during the past year. The object of the institution is to provide a temporary residence with medical care for ladies of limited means who are likely to be benefited by wintering in a dry warm climate. The inclusive charge made is $25 \mathrm{~s}$. a week. Applications for admission, accompanied with a certificate as to social position and means, and a medical certificate, may be sent to either of the secretaries, Mrs. Daniel, Villa Emily, San Remo; or Miss Kay Shuttleworth, 55, Aughton Street, Southport, from whom the blank forms may be obtained. 